EGU2020-2711

https://doi.org/10.5194/egusphere-egu2020-2711

EGU General Assembly 2020

(c) Author(s) 2020. This work is distributed under

the Creative Commons Attribution 4.0 License.

\title{
Centre-pivot irrigation system design for uniform water application rate
}

Giorgio Baiamonte, Mustafa Elfahl, and Giuseppe Provenzano

University of Palermo, Department Agricultural, Food and Forest Sciences (SAAF), Palermo, Italy

(giorgio.baiamonte@gmail.com)

In the last few decades, the use of centre-pivot irrigation systems has significantly increased, since it makes farming easier, is more efficient and less time-consuming compared to the other irrigation systems. Several studies have been focused on the hydraulics of the centre-pivot systems. Standard high-pressure impact sprinklers or low-pressure spray sprinklers or Low Energy Precision Application (LEPA) systems are generally mounted on the pipeline.

To ensure the uniformity of water application, the centre-pivot design requires increasing the flow rates along the lateral, because the sprinklers farther from the pivot move faster, and therefore their instantaneous application rates must be greater. Thus, the irrigated area under a centrepivot system expands substantially with increasing system length. To irrigate the increased area by maintaining constant the application intensity, the manufacturers propose: i) to increase the flow rates of equally spaced sprinklers, ii) to gradually decrease the spacing of equal-flow sprinklers along the centre-pivot lateral, and iii) to use semi-uniform spacing, which is a combination of the first two methods.

However, the most common centre-pivot systems have equally spaced sprinklers with increasing flow rates (nozzle sizes) along the lateral, which is probably the easiest method from a practical point of view. Although many definitions and design procedures can be found in the technical literature, a universally accepted design procedure has not yet been found. In fact, the issue of centre-pivot irrigation system design is widely debated and there is still a need for simple, yet adaptive designing guidelines for farmers using these systems, specifically to maximize water use efficiency.

This study presents an alternative design procedure of centre-pivot irrigation system allowing to set favourable water application rates. First, the sprinklers' spacing distribution corresponding to a fixed irrigated area along the radial direction is derived. According to this outcome, the results showed that sprinkler characteristics and/or pipe diameter need to be varied along the lateral, based on the desired and uniform water application rate. Then, for a practical case, an application based on the proposed hydraulic design procedure was performed and discussed. 